\title{
Invited article: Adaptability
}

\author{
Olivia Parr Rud \\ OLIVIAGroup \\ Postal Address: Contact author via email \\ Phone: +215-94 83 500; Fax: +215-89 58850 \\ E-mail: Olivia@oliviagroup.com
}

We must remain open to change by building flexibility into our organizational structures and interactions. The more rigid we become, the less access we have to the reality of the system, and thus, the less able we are to shift as the environment demands.

\section{- Julie Roberts Ph.D., Principal of ChangeWorks}

\begin{abstract}
For the last several decades, organizations have dealt with economic shifts using change management. Based on the new science, there are two major flaws with this approach. First, the word change implies an event with an ending. Second, it implies that change can be managed. In a world of economic volatility, this approach is no longer viable. The continuous climate of uncertainty and volatility demands another view, one that supports adaptability and resilience.
\end{abstract}

Key words: Organization, alignment, speed of change, economic volatility, market shift, Total Quality Management, Business Reprocess Engineering, living systems, chaos, evolution, fifth discipline, learning organization, system thinking.

\section{JEL Classification: MOO, M21, M50}

Invited paper is published previously as a chapter in a book "Business Intelligence Success Factors: Tools for Aligning Your Business in the Global Economy", Copyright C 2009 Olivia Parr Rud. Reprinted with permission of John Wiley \& Sons, Inc.

\section{The Shifting Paradigm}

Risk management's inability to adapt to the changing business landscape played a large role in the global financial meltdown.

- Daniel Tu, PricewaterhouseCoopers

An adaptable organization is one that self-organizes. Most organizations appear to have order. But order is not the same as organization. Organization involves differentiation and specialization (Wheatley, 1992).

To understand the basic reasons for the resistance to evolve, it is instructive to trace the roots of our traditional business models. The organizational model that serves as the foundation for most companies has its origins in Newtonian physics, which states that all "individual or system behavior is knowable, predictable, and controllable" (Olsen, Eoyang, 2001). It operates like a machine "with each part acting on the other part with precise linear laws of cause and effect" (Hollman, 2003). This structure brings with it many aspects of mechanistic thinking, some of which are useful. But in a highly volatile economy, most aspects of this model are inefficient. For example, most companies have rigid organizational structures with centralized command and control. Their business intelligence systems are linear and unidirectional. They utilize rigorous analysis and measurement to limit variation and drive efficiency, and, in the event of an unpredicted outcome, they search for root causes. They tend to be highly mechanized companies with highly specialized workers who receive extensive instructions. This model is useful in stable environments, such as operating rooms or highly specialized factories, where systems are closed, change is slow, and variability is low (Olsen, Eoyang, 2001, a).

\section{Traditional Methods}

Traditional change methodologies designed for the mechanistic model are typically "rational, top-down, expert-driven, and planned" (Olsen, Eoyang, 2001, a). And even though nearly three-fourths of change initiatives, such as total quality management or reengineering, fail, most organizational change initiatives still operate under these models (Olsen, Eoyang, 2001, a).

\subsection{Total Quality Management}

Total quality management (TQM), for example, is defined by the International Organization for Standardization as "a management approach for an organization, centered on quality, based on the participation of all its members and aiming at long-term success through customer satisfaction, and benefits to all members of the organization and to society" (TQM, http://en.wikipedia. org/wiki/TQM). "One major aim [of TQM] is to reduce variation from every process so that greater consistency of effort is obtained (TQM, http://en.wikipedia.org/wiki/ TQM)".

This approach is based primarily on the philosophy of Dr. W. Edwards Deming, pioneered in the 1930s and 1940s. However, he later abandoned the terminology of TQM "because he believed it had become a superficial label for tools and techniques." "The real work, which he simply called the "transformation of the prevailing system of management," lay beyond the aims of managers seeking only short-term performance improvements. This transformation [...] required "profound knowledge" largely untapped in contemporary institutions (Senge, 1990). 
In a letter to Peter Senge, Dr. Deming (then almost 90) wrote: "Our prevailing system of management has destroyed our people. People are born with intrinsic motivation, self-respect, dignity, curiosity to learn, joy in learning. The forces of destruction begin with toddlers-a prize for the best Halloween costume, grades in school, gold stars - and on up through university. On the job, people, teams, and divisions are ranked, reward for the top, punishment for the bottom. Management by Objectives, quotas, incentive pay, business plans, put together separately, division by division, and cause further loss, unknown and unknowable (Senge, 1990)".

\subsection{Business Process Reengineering}

Business process reengineering (BPR) is based on a theory by Frederick Winslow Taylor that variation is waste. It actually makes sense for areas within a business that are highly linear and measured. Originally conceived as a way to reshape processes, it became the rationale for the massive layoffs in the 1990s that had such a disastrous effect on the economy. "Its bias toward static, written rules means it cannot handle the abstract, dynamic thinking and actions of humans in a knowledge based economy" (Bennett, Hedlund, 2009). By imposing actions from outside, it ignores the knowledge of the people within the system and undermines their value in the process of realignment.

\section{The New Paradigm}

In traditional organizations, strategy management is usually static and reductionist. The focus is on shortterm gain, optimal allocation of resources, process improvement, and increasing competitive advantage. The approach to change is incremental, with the assumption that a slight change in the existing strategy or variation in the organizational structure will do the job.

As mentioned earlier, two fundamentally different organizational models are offered. The traditional model, based on Newtonian science, is linear, rational, and reductionist. It is based on the idea that organizations are made up of individual units that can be managed separately. Units such as people, products, tasks, and expenses can each be optimized to support the whole. Change as predictable and controllable with a final end state characterized by stability. According to Laszlo and Laugel (2000) in Large-Scale Organizational Change, "This notion is rooted in calculus with which Newton expressed his immutable laws of physics-smooth, continuous, differential equations that lead toward a fixed equilibrium".

The emergent model is on the opposite end of the spectrum. It sees organizations as emerging from complexity with their parts interconnected and relating as living systems. Behavior emerges and is experienced on an organizational level. It cannot be reduced to incremental units. Rather than implementing change, the emergent or living systems model is always adapting to stay in balance. Change, as defined by the old model, is continuous. The wisdom or intelligence of the organization does not just reside with leadership but is assumed to be distributed across a wide variety of people and systems.

By understanding the rules, principles, and behaviors of each model, organizations can select the best path based on the specific situation. For example, if a company needs to manufacture a product, a clear linear process with a predefined path and time frame is optimal. However, when pressures from outside or deep within an organization require adaptation, it is rarely predictable or controllable. The constant need to innovate, a pressure felt by many in the global economy, is a good example. The intelligence of the organization to meet this goal is far superior to that of the top management team (Laszlo, Laugel, 2000).

Table 1 highlights the comparison between Classical Science and the New Science. The results of each of these paths are shown in Table 2.

To illustrate how our traditional change methodologies and structures limit adaptability, imagine if traditional business rules and processes are applied to the neurons in the brain.

Organize the neuron in your brain, the most complex, infinitely diverse organ that has ever emerged in evolution, as you would a corporation. The first thing you've got to do is appoint the Chief Executive neuron, right? Then you've got to decide which are going to be the Board of Directors neurons and the Human Resources neurons, and then you have to write an operating manual for it. Now, if you could organize your brain on that model, what would happen? You would instantly be unable to breathe until somebody told you how and where and when and how fast. You wouldn't be able to think or see. What if your immune system were organized on this basis? First you'd have to do some market research to determine what virus, if any, was attaching you, right? Then you'd have to have marching orders for all the various aspects of your immune system (Hoffman, 2003).

\section{Models for Adaptive Organizations}

Chapter 2 of the book "Business Intelligence Success Factors" offered complexity science, chaos theory, and evolutionary biology as models for understanding organizational dynamics in a volatile economy. Further exploration into various aspects of these models unveils concepts for improving organizational adaptability. 
Table 1. Comparison between Classical Science and New Science

\begin{tabular}{|l|l|}
\hline Classical Science & New Science \\
\hline Mechanistic, linear, separate parts, events, moments. & Holistic, nonlinear, integrated. \\
Whole is defined as sum of parts. & Whole is greater than sum of parts. \\
Reality is predictable; laws determine the outcome. & Reality is full of possibility; nothing is predetermined. \\
"Either/or" thinking. & "Both/and" thinking. \\
Work with building blocks. Those in control dictate & Work with networks. System is emergent and self- \\
what is done. & referencing. \\
Chaos is suppressed; structures are taken apart to & Natural order emerges from chaos; self-organization. \\
examine and control. & \\
Science is objective; what is not observed does not & No objective reality; our observations evolves; we \\
exist. & cannot avoid having an impact. \\
Seek the truth. & Seek best approximation of reality. \\
\hline
\end{tabular}

Table 2. Results of Paths in Table 1.

\begin{tabular}{|l|l|}
\hline Classical Science & New Science \\
\hline Closed rigid systems & Flexible open systems \\
Resistance to chaos & Willingness to leverage chaos \\
Passive hostility to beeing controlled & Creativity, adaptability, energy \\
Lack of information & Flow of information through natural connections \\
Low value placed on relationship & Relationships emerge and flourish \\
Fear during change & Support during change \\
Fragmentation & Harmony \\
\hline
\end{tabular}

\subsection{A Living Systems Model}

Leading an organization based on living systems requires an understanding of organizational evolution (Laszlo, Laugel, 2000). "The focus shifts from what is to what is becoming, from structure to dynamics." The following steps describe the pattern of change in living systems:

- Innovation

- Complexification and Convergence

- Bifurcation and Chaos

The steps originate in science but have a direct application in the corporate world. Their role and interrelation are critical to understanding adaptability in an emergent organization.

Innovation. Innovation is essential for maintaining adaptability and resilience. The combination of advances in technology and globalization put pressure on many organizations to adapt or die. Both of these are seen as irreversible. And the speed at which they occur continues to increase. The impact of a high level of innovation is felt through the next step.

Complification and Convergence. As advanced technologies inject new information into the system, complexity increases. However, there are limits to the complexity an organization can handle. To accommodate increased complexity, new levels of organization must be created to control and coordinate the existing levels. As a result, an organization "always converges progressively toward more embracing and coordinated multilevel structures."

Convergence is seen across the globe as many corporations are partnering, forming alliances, merging, 
and diversifying into multiple lines of business. Global business standards and regulations are a result of this phenomenon.

What happens when a global company reaches its limit of complexity is unknown. Based on the new science, the next step in the sequence may be chaos.

Bifurcation and Chaos. Scientists have known for decades that as complex systems evolve, chaos and uncertainty increase. Today, computer models are able to simulate the evolutionary path with mathematical precision. The models show the attractors that form the pattern of the evolutionary trajectory.

The evolutionary trajectory can be plotted to show a graphical pattern providing a visual depiction of an attractor. There are several types of attractors. A system that evolves toward a fixed point over time is defined by stable-point attractors; a cyclically recurring state is characterized by period attractors; and an emergent system of order is defined by strange or chaotic attractors. As chaotic attractors are plotted, a shape emerges that has definite boundaries and patterns. The beautiful shapes of the plots prove that chaotic attractors are neither arbitrary nor disorderly.

Bifurcation occurs when a complex system changes trajectory. It is characterized by a change in pattern and a shift from one set of attractors to another. In the real world, complex systems evolve out of a specific initial state until a pattern emerges. If the evolution comes to rest, the process is ruled by static attractors. If the patterns are cyclical, the system is regulated by periodic attractors. If neither of these occurs, the system is controlled by strange or chaotic attractors.

Strange or chaotic attractors are pervasive in our global economy. The recent collapse of the world's financial markets and its domino effect around the world demonstrates this pattern. Catastrophic bifurcations are occurring as many large financial institutions seek equilibrium amid the chaos.

Chaotic attractors do not operate with total randomness. Scientific analysis has unveiled a subtle order that emerges. Complex systems self-organize through a natural phenomenon known as cross-catalytic cycles. Following periods of instability and chaos, these cycles allow complex systems to return to dynamic stability where they can grow and prosper.

\section{Leveraging Chaos in Organizations}

As mentioned earlier, the key to leveraging chaos within an organization is to allow the vision to drive the change. Chaos manifests within organizations as an inability to find and deal with information in a useful way. If the chaos is contained within specific boundaries, and if the members of the organization can tolerate the tension, order will eventually emerge. Crisis, however, is the failure of coping mechanisms, resulting in a loss of a framework that leads to stagnation or death. In other words, the system is unable to tolerate the tension.

Vision-driven energy can create change that does not result from crisis, although chaos will still occur. Dissatisfaction with the status quo drives a vision, not crisis. Dissatisfaction is the result of examining the status quo with an open mind in relation to the environment and deciding that change is necessary. The vision provides a way of getting members of the organization focused on the future. A vision should inspire and motivate. It should entice members to move out of the current state and move toward the new state while honoring the values of the organization and its members.

\subsection{Structure within Chaos}

For organizations to foster adaptability, it is important to provide a structure or boundaries to guide it through the chaos. However, there is a delicate balance between providing structure and controlling the process. Recall that new patterns emerge only when the system is far from equilibrium. Providing structure in this case means utilizing the system, getting people together and providing them with ways of interacting, and sharing information. This process provides the tension thhat results in people feeling the need to change. In a healthy system, they would eventually create a plan together. "No one system dictates conditions to another. All participate together in creating the conditions of their interdependence" (Wheatley, Kellner-Rogers, 1996).

When an organization is in chaos, leaders typically decide they know the answers and take it upon themselves to establish the necessary structures, processes, and rules without any input from the rest of the organization. While this approach is generally easier and faster, it is antithetical to systems thinking and may impede adaptability. It actually prevents the system from rising to a higher level by way of self-organization. Systems thinking require that the all parts of the system be involved in any major decision-making process.

When chaos is overwhelming the system, it is necessary to provide boundaries or simple rules to contain the chaos. Doing so entails helping people stay focused on the core purpose of the organization and values. By allowing employees to experience the underlying strength of the organization, everyone in it is able to understand and internalize the core purpose. However, it is critical to create dialogue opportunities that encourage tough questions regarding the purpose and its impact. It is common to assume that everyone understands the purpose; thus, often this step is skipped. Understanding 
the core purpose is crucial in self-organizing systems; this purpose provides the goals around which selforganization occurs. Dialoguing regarding purpose aligns individuals and helps them to claim the purpose as their own.

Values are guiding principles for how to act. They define members' behavior in reaching their goals. An example of a value is: "We will continue to learn and evolve by examining what we do and how we do it on an individual, group, and system level." Values act as the strange attractor that pulls the system into order during times of turbulence. They provide guidelines for how to interact with one another, particularly during chaos. Without clear standards for how to work and interact, change can be too risky.

It is futile to have values that mean nothing and do not define how people actually behave. If people hear one value and see behavior that contradicts it, they will not feel safe. For example, if an organization values selfexamination and criticism to aid learning and then uses blame and punishment when something goes wrong, the self-examination will cease. In addition to consistency around behavior, it is important for leaders to model the desired organizational behavior.

\subsection{Tolerance for Discomfort}

Systems change when they are far from equilibrium. For this reason, it is important to resist complacency in times of success. Many organizations fail as a result of complacency. Organizations that continue to look for indicators of new shifts will maintain a competitive edge.

It is helpful to develop a tolerance for the discomfort associated with the change process. Doing so allows natural connections to develop. But when discomfort reaches high levels, some organizations hurry the process by forcing connections, coming to premature solutions, and controlling outcomes. This control impedes the formation of natural connections. Newly formed groups, which are particularly susceptible to this urge, cope with it by jumping to solutions prematurely. During times of change, the urge to bring closure to issues and to know the answers increases. This urge needs to be managed with forethought and care by developing a tolerance for ambiguity and lack of control.

\subsection{Natural Connections and Flexibility}

Order rises naturally from chaos, and connections form naturally to make sense of the inherent and emerging information. Organizational structures and processes should be formed as a result of natural connections, and they should be adapted when necessary to ensure that the vision is achieved in the most productive and efficient manner. Jan Carlzon, chief executive of Scandinavian
Airline System, made the organization legendary by (among other things) simplifying its rules. He burned thousands of pages of manuals and handbooks to demonstrate how overrun the organization was with rules (Heifetz, Laurie, 1997). If rules and processes are rigid and inflexible, the organization will not be able to shift at the appropriate time.

Six guidelines for staying flexible include:

(1) Be patient when allowing connections to form.

(2) Avoid becoming rigid with or overrun by structures, rules, and processes.

(3) Make sure the rules and processes that are in place are relevant and necessary.

(4) Solicit regular feedback.

(5) Stay open to new ways of doing things.

(6) Make sure suggestions and ideas are fully understood before discarding them.

\subsection{Evolution at the Edge}

It is important to acknowledge that the discomfort created by chaos is necessary for change to occur. It is equally important to safeguard against getting lost or frozen in the midst of the chaos. Leaders need to balance on the edge of chaos, dipping in and being comfortable there in order to move themselves and the organization to higher levels of evolution. This delicate balance includes inviting members of the organization to feel the need for change while not feeling overwhelmed by it. According to Coveney and Highfield (1995) in Frontiers of Complexity, "[C]omplex systems that can evolve will always be near the edge of chaos, poised for that creative step into emergent novelty that is the essence of the evolutionary process".

The edge of chaos is the best place to observe the patterns of order available, patterns that then may be applied to the current situation. Getting stuck in one particular state of order is not effective because, sooner or later, that state will become obsolete. It is crucial for leaders to remain open to new experiences that the environment contains and show a willingness to adapt and change based on the information received from the environment.

Emotional Distance. The ability to move gracefully in and out of change and the resulting chaos requires an ability to observe what is happening. Doing so involves being able to psychologically step back and assess what is occurring on multiple levels with detachment. If participants become emotionally involved, it becomes difficult for them to be objective.

Emotional distance allows participants to observe with an open mind, thereby enhancing the likelihood that they will hear other points of view and see what is occurring in a group. This is the reason why it is often suggested that facilitators not participate in the content of a discussion. They are then more able to see what is going on and 
make helpful interventions, dipping in when necessary to keep the group on course or help members deal with something they are avoiding.

What to Observe at the Edge. It is helpful to observe specific aspects of the group while maintaining emotional distance by asking:

- Are the goals clear?

- Are people listening to one another and communicating well?

- Are individuals involved and included?

- How are people feeling (what are their nonverbal expressions, what they are doing, how are they interacting)?

All of this information will help to identify clues regarding the health of the group, its relationships, and its interactions in the organization. If ineffective interactions are apparent, an intervention will help move the group to greater effectiveness. For example, if people are not listening, the facilitator can ask others to repeat what was just said. If goals are not clear, the facilitator can ask the group to clarify them. If the group is moving off task, the facilitator can ask if this is what the group should be doing. If someone looks angry or confused, the facilitator can ask him or her how they are doing. Another way of observing group effectiveness is to look for patterns in the organization, which is discussed in the next section.

Fractals. Discovered by Benoit Mandelbrot in the 1970s, fractals provide a guide for examining complexity and patterns. They are characterized by patterns that replicate to create the whole. In a fractal, each part is autonomous. However, the pattern of each part is embedded in every part of the whole. Some common examples of fractals are the lungs, circulatory systems, leaves, and feathers. Fractals contain a certain order that allows them to be decoded with a few rules. Complexity is the result of a given structure being repeated many times.

Fractals can be seen within the social life of an organization. Each member is autonomous while it is part of the greater whole. The organization is healthiest when members' patterns are replicated throughout the whole through effective communication.

Leaders are fractals of others in the organization. Their behavior is often mirrored throughout the organization. If the leader is collaborative, communicates openly, and attempts to learn from past mistakes, this behavior will carry through to the members.

Norms as Fractals. Norms for behaving are patterns that can be observed in the organization. Much like a fractal, an organization is seen as connected if certain norms exist throughout it. Norms are the implicit or explicit rules that guide and determine what behaviors are acceptable within a group. Although often not explicit, these are the rules by which people work on a daily basis. They determine how a group handles conflict and stress, makes decisions, listens, generates ideas, and allows certain language to prevail. In any group, norms may be effective or ineffective.

An example of an organizational norm is the way a group deals with conflict. For example, some organizations suppress tension by pretending it is not there. Nonverbal cues, such as frowns, crossed arms, and downward glances, are ignored while the group goes on to the next agenda item. This norm keeps the group from examining what is occurring, from sharing thoughts, feelings, and disagreements. These unresolved feelings and disagreements then go underground and sabotage the group later because they have not been resolved. Avoiding conflict cuts off important sources of information that could possibly improve the team, the product, and the way things are done.

Healthy norms are patterns in the organization that can:

- Encourage continuous open feedback, both negative and positive.

- Encourage people to share thoughts and feelings.

- Encourage individuals and groups to deal with conflict.

- Allow learning from mistakes, without blame or judgment.

- Create a flow of information throughout the organization.

- Encourage participation and involvement in decisions.

Each of these norms facilitates the emergence of a truly adaptable organization. All of these norms must be aligned with and support the desired values to ensure that those values permeate the organization. These values are in harmony with the principles that support living systems. As they become institutionalized, healthy norms will come to characterize the organization (Roberts).

\section{Conflict Resolution: A Living Systems Approach}

Conflict is a natural by-product of the tensions that arise in dynamic organizations. Although it is often perceived as negative, conflict that is handled effectively has the potential to inject new, creative energy into the system.

Conflict can be dealt with in a variety of ways. The use of mediation along with the practice of effective listening skills detailed in Chapter 3 of the book "Business Intelligence Success Factors" is often successful. Organizations are discovering that by inviting individuals to work through their issues in new positive constructive ways that tap into the energy of the group, these techniques deepen the connections within and across their teams.

Eric Brunner, manager of Human Resources at Temple 
University and his colleague, Marie Amey-Taylor, director of Temple's Human Resources Department, use a variety of training techniques that provide content in visual, auditory, and kinesthetic formats. They also design their trainings to be active, using both inductive and deductive activities to transfer learning to the participants.

For over 10 years, Brunner and Amey-Taylor have been practicing a combination of improvisational theater and sociodrama to demonstrate appropriate and inappropriate conflict resolution skills and ways to work through conflict and build trust. Sociodrama is a form of improvisational theater based on the "shared central needs and issues" of the audience or participant group and involves dramatic enactments of real-life situations or conflicts so that participants can observe and develop interpersonal skills. It is presented using trained actors, occasional volunteer audience members, and a highly trained facilitator. In practice, Brunner and Amey-Taylor found that participants became very engaged in the action, would dialogue with the characters in a scene, and might even jump in to take the place of actors to "correct" inappropriate or ineffective behaviors. This unique combination of improv and sociodrama is a powerful technique and has become a staple in their work with employees at all levels within a wide variety of organizations. In the next section, Brunner shares his experience with the process.

Conflict Resolution with Sociodrama. Recently, we were asked to partner with a professor from Temple University's School of Communications and Theater who was presenting on the topic of cross-cultural communication at a women's leadership conference at Bryn Mawr College. In attendance were about 80 women, all high-level administrators, from a wide range of institutions of higher education. Because the group was all women, there was a content piece based on the work of Deborah Tannen, an expert in the different communication styles of men and women. Prior to the presentation of this content area, the theater troupe presented a scene designed to introduce the content and invite participants into the presentation. Because of the actors' familiarity with the participant group and the program content, they were able to anticipate a scene that would have relevance for the group and introduce content. There were four actors on site for this session, two men and two women.

The scene started with actors playing the four people responsible for planning an event on a college campus. During the enactment, the male actors began acting in ways that were illustrative of how Tannen described men as communicators. And the women in the scene began acting in the ways that she described as typical of women. As the scene played out, the session participants were able to see the connection between cross-gender communication and the possible conflicts that could be generated. As the group saw themselves and others with whom they work in the characters, they started to react, most with laughter. A few exhibited a heightened desire to rectify the situation depicted by the actors. After watching the enactment for five minutes, the group participants were engaged and eager to explore the topic more fully. The use of theater also allowed the women to release some of the feelings they carried related to the topic and their own experiences. This purely experiential format for generating discussion and learning about conflict has proven to be an effective training technique and a tool for building trust and strong relationships

\section{The Learning Organization}

The technology driven enterprise demands a new leadership paradigm - one that creates a far stronger, more genuine link between the achievement of corporate objectives and the employee's realization of his deepest, often unexpressed, intensely personal growth needs. Thus, rather than the mere promise of greater corporate status and power, followership is borne of belief in the leader's true understanding and caring for the employee's holistic being and welfare, and thus flows from greater intimacy.

Kendall A. Elsom, Jr., President, CEO Genesis Consulting Partners

In The Fifth Discipline, Peter Senge (1990) introduces five new component technologies, or disciplines that "are gradually converging to innovate learning organizations". They are systems thinking, personal mastery, mental models, building shared vision, and team learning. According to Senge (1990), organizations that practice these disciplines are adaptable, self-organizing, and have the potential to "continually enhance their capacity to realize their highest aspirations".

\subsection{The Five Disciplines}

Systems Thinking. As described in Chapter 2 of the book "Business Intelligence Success Factors", systems thinking take the approach that to have impact; the organization needs to be viewed in its entirety with recognition that the whole is greater than the sum of its parts. While one participates in a system, it is sometimes difficult to see the overall pattern and how that pattern changes over time. Since parts of organizations are connected by numerous interactions, the effect on other parts may take years to play out.

Traditional approaches tend to view each part in isolation, often never getting to some of the deepest issues. Senge (1990) defines systems thinking as "a conceptual framework, a body of knowledge and tools that has been developed over the past fifty years, to make the full patterns clearer, and to help us see how to change them effectively". 
Personal Mastery. Senge (1990) defines personal mastery as "the discipline of continually clarifying and deepening our personal vision, of focusing our energies, of developing patience, and of seeing reality objectively". As someone might strive for master status within a trade, mastery is a special level of proficiency or selfactualization. It is a foundational element of the learning organization since "an organization's commitment to and capacity for learning can be no greater than that of its members" (Senge, 1990).

Unfortunately, this is where many organizations fall short, leading to vast untapped potential. Most people enter business full of optimism and energy. But after a number of years, they become disenchanted and just put in their time until retirement with minimum effort. Therefore, it is critical for management to hire and inspire toward the goal of each member striving for personal mastery.

Mental Models. Senge (1990) defines mental models "as deeply ingrained assumptions, generalizations, or even pictures or images that influence how we understand the world and how we take action". A majority of these models are unconscious and have existed since childhood. Yet they pervade every thought, word, and action.

The first step in dealing with mental models is to look within oneself. Then the organization must create a safe place for members participate in compassionate scrutiny and influence through the process of "inquiry and advocacy."

Building Shared Vision. One thing that all successful organizations have in common is a shared vision. Made up of shared goals and values, a shared vision has the capacity to bring "people together around a common identity and sense of destiny" (Senge, 1990). It unleashes creative energy and fuels innovation by rallying diverse members in a shared vision that galvanizes the organization. It "involves the skills of unearthing shared 'pictures of the future' that foster genuine commitment and enrollment rather than compliance" (Senge, 1990).

Team Learning. The success of organizations to learn is based on the ability of the teams to learn. The team must connect and share through dialogue while suspending assumptions and learning to trust each other. Blocks such as fear, apathy, and defensiveness can undermine learning. Therefore, safe and open communication is essential.

Team learning has the power to enhance capabilities for innovation and creativity. But to maximize the benefits, the learning must be shared. Many teams of brilliant individuals have produced mediocre results due to lack of interaction and integration. Practicing team learning is not about copying a model. Many new management innovations emerge as "best practices."
But most organizations adopt and implement the ideas in a piecemeal fashion. Toyota is a great example of a company that uses a systems approach. Many companies copy Toyota's kanban system. But they fail to see how all the parts work together in a way that is unique for Toyota.

\section{The Fifth Discipline}

Senge (1990) points out that "[i]t is vital that the five disciplines develop as an ensemble". This is truly a time when the total is greater than the sum of its parts. Based on that truth, "system thinking is the fifth discipline." Without a systemic approach, the coherence necessary to be adaptable is lost. "For example, vision without systems thinking ends up painting lovely pictures of the future with no deep understanding of the forces that must be mastered to move from here to there" (Senge, 1990).

Organizations that embrace systems thinking must also practice "the disciplines of building shared vision, mental models, team learning, and personal mastery to realize its potential." Each of these disciplines plays a role in powering the system. Shared vision builds a group commitment to the future. Mental models provide the openness necessary to unveil the limitations present in the organization. Team learning improves the members' skills to create and take action on an organizational level. And personal mastery encourages the self-reflection, healing, and personal growth necessary to fully participate in an adaptable organization.

Finally, learning organizations offer amazing potential for creating their future. Based on the new science, a learning organization is creating its future by shifting how individuals perceive themselves and their world.

\section{Conclusion: A New Global Organization}

As stated earlier, the information explosion coupled with advances in technology and globalization are placing stress on organizations to adapt. Companies stuck in the old hierarchical structure often are based on closed systems with separate units defined by activities and offerings. The organizational management chart looks like a tree with each position branching off from the one above.

A dynamic, emergent organization, however, has an organizational chart that is very nonlinear. It bears more resemblance to a network of relationships or groups of overlapping circles. This living-systems model enables an optimal flow of information leading to higher resiliency and innovation.

Chapter 7 of the book "Business Intelligence Success Factors" offers some guidance for individuals taking on a leadership role in adaptable organizations. 


\section{References}

1. Bennett, J. W., Hedlund, S. B. (2009). In a Slump? Realign, Don't Re-Engineer, www.strategy-business. com/press/enewsarticle/22710, Accessed: October, 2011.

2. Coveney, P., Highfield, R. (1995). Frontiers of Complexity: The Search for Order in a Chaotic World. Fawcett Columbine, New York.

3. Heifetz, R., Laurie, D. (1997). The Work of Leadership. Harvard Business Review, http://www.ncsl.org.uk/ media-f7b-97-randd-leaders-business-heifetz.pdf, Accessed: October 2011.

4. Hoffman, M. (2003). Transformation by Design, An Interview with Dee Hock. Enlightenment Magazine, No. 22, 131.

5. Laszlo, C., Laugel, J. F. (2000). Large-Scale Organizational Change. Butterworth Heinemann, Boston.

6. Olsen, E. E., Eoyang, G. H. (2001) a. Facilitating Organizational Change, 3. Jossey-Bass/Pfeiffer, San Francisco

7. Olsen, E. E., Eoyang, G. H. (2001). Facilitating Organizational Change, 2. Jossey-Bass/Pfeiffer, San Francisco

8. Roberts, J. Leading with Heart and Soul. Manuscript.

9. Senge, P. M. (1990). The Fifth Discipline. Currency, New York.

10. TQM, http://en.wikipedia.org/wiki/TQM, Accessed: October, 2011.

11. Wheatley, M. J. (1992). Leadership and the New Science. Barrett-Koehler, San Francisco.

12. Wheatley, M. J., Kellner-Rogers, M. (1996). A Simpler Way. Barrett-Koehler, San Fransisco.

Olivia Parr Rud is an internationally recognized expert in business intelligence and organizational alignment. She is considered a thought leader in the integration of analytic tools and leadership practices that lead to optimal performance and adaptability. Her research in business intelligence led to the writing of her first book, Data Mining Cookbook, Modeling for Acquisition, Risk and CRM (Wiley 2001). This led to the unveiling of links between the global economy and organizational dynamics, highlighted in her second book, Business Intelligence Success Factors, Aligning for Success in a Global Economy (Wiley/ SAS, 2009). Olivia has a Bachelor of Arts in Mathematics and a Master of Science in Statistics. Clients include Cisco, Wal-Mart, Wells Fargo, HP, IBM, and Xerox. 